\title{
Article
}

\section{Evaluation of students' performance and engagement using post-laboratory integrated assessments within a pharmacy course in the United Kingdom: a pilot cohort cross-over study}

Lunn, Andrew, Cogan, Louise Siobhan and Manfrin, Andrea Available at http://clok.uclan.ac.uk/36490/

Lunn, Andrew ORCID: 0000-0003-2884-2755, Cogan, Louise Siobhan ORCID: 0000-0001-9835-1981 and Manfrin, Andrea ORCID: 0000-0003-3457-9981 (2021) Evaluation of students' performance and engagement using postlaboratory integrated assessments within a pharmacy course in the United Kingdom: a pilot cohort cross-over study. Currents in Pharmacy Teaching and Learning, 13 (5). pp. 449-459. ISSN 1877-1297

It is advisable to refer to the publisher's version if you intend to cite from the work. http://dx.doi.org/10.1016/j.cptl.2021.01.010

For more information about UCLan's research in this area go to http://www.uclan.ac.uk/researchgroups/ and search for <name of research Group>.

For information about Research generally at UCLan please go to http://www.uclan.ac.uk/research/

All outputs in CLoK are protected by Intellectual Property Rights law, including Copyright law. Copyright, IPR and Moral Rights for the works on this site are retained by the individual authors and/or other copyright owners. Terms and conditions for use of this material are defined in the policies page. 


\section{Evaluation of students' performance and engagement using post-laboratory integrated}

assessments within a pharmacy course in the United Kingdom: a pilot randomised cross-over study

Andrew Martin Lunn $*$, Louise S. Cogan, Andrea Manfrin

School of Pharmacy and Biomedical Sciences, Maudland Building, The University of Central Lancashire, Preston, Lancashire PR1 2XT, United Kingdom

\section{Abstract}

Introduction. This pilot study investigated the impact of practice integrated, post-laboratory assessment on the scientific education and attitudes of first-year pharmacy students. Median performance in assessment, achievement of full marks and engagement in laboratory classes was evaluated.

Methods. A pilot randomised cross-over study was conducted at the University of Central Lancashire. Students were randomly assigned to two groups and after undertaking four identical pharmaceutics laboratory classes, answered two science-based questions that were either integrated with practice using a contextualizing scenario or had no integration. Their performance and engagement were subsequently analysed. Un-paired dichotomous values were assessed using Pearson's chi-square for independence or goodness of fit, Fisher's exact test, Cochrane Q. Paired dichotomous values were assessed using McNamara's test. Students' scores of integrated and non-integrated assessments were analysed using linear regression. Students' engagement was also assessed, using the ASPECT questionnaire. Continuous data were generated and analysed using descriptive statistics, Wilcoxon sing-rank test, Mann-Whitney $U$ test.

Results. Thirty students completed the study. Students performed better in the integrated assessment (median=3.5; IQR=2.00-4.00) compared to non-integrated $(2 ; 1.75-3.00)(p=0.003)$. Twenty-five students $(83 \%)$ achieved full marks with integrated assessment $(p=0.006) . R^{2}$ for the integrated assessment was 0.90 , for non-integrated 0.12 . Students' engagement was positive in both groups but significantly improved in the domains of "Instructor contribution" and "Value of activity" $(p=0.011)$ when receiving the integrated assessment.

Conclusions. Integrated and contextualized assessment of science teaching as a lone intervention increased pharmacy students' performance and engagement in laboratory classes without any change to the teaching session itself.

Keywords. Pharmacy; education; integration; assessment; contextualization. 
Conflict of interest statement The authors whose names are listed immediately below certify that they have NO affiliations with or involvement in any organization or entity with any financial interest (such as honoraria; educational grants; participation in speakers' bureaus; membership, employment, consultancies, stock ownership, or other equity interest; and expert testimony or patent-licensing arrangements), or nonfinancial interest (such as personal or professional relationships, affiliations, knowledge or beliefs) in the subject matter or materials discussed in this manuscript.

Disclosures. There are no disclosures to declare

\section{Introduction}

\section{Background/Rational}

Scientific laboratory teaching is incorporated across all Master of Pharmacy (MPharm) programmes in the United Kingdom. Understanding the basic principles behind medicinal development is crucial to ensure that the students are equipped with the knowledge required to understand future developments in the area and become "medicines experts". ${ }^{1}$ The General Pharmaceutical Council (GPhC) suggest that the initial education and training of pharmacists must include an integrated experience of relevant science, where students must know and show how "the science of pharmacy is applied in the design and development of medicines and devices"2

Figure 1 Adaptation of Bloom's taxonomy

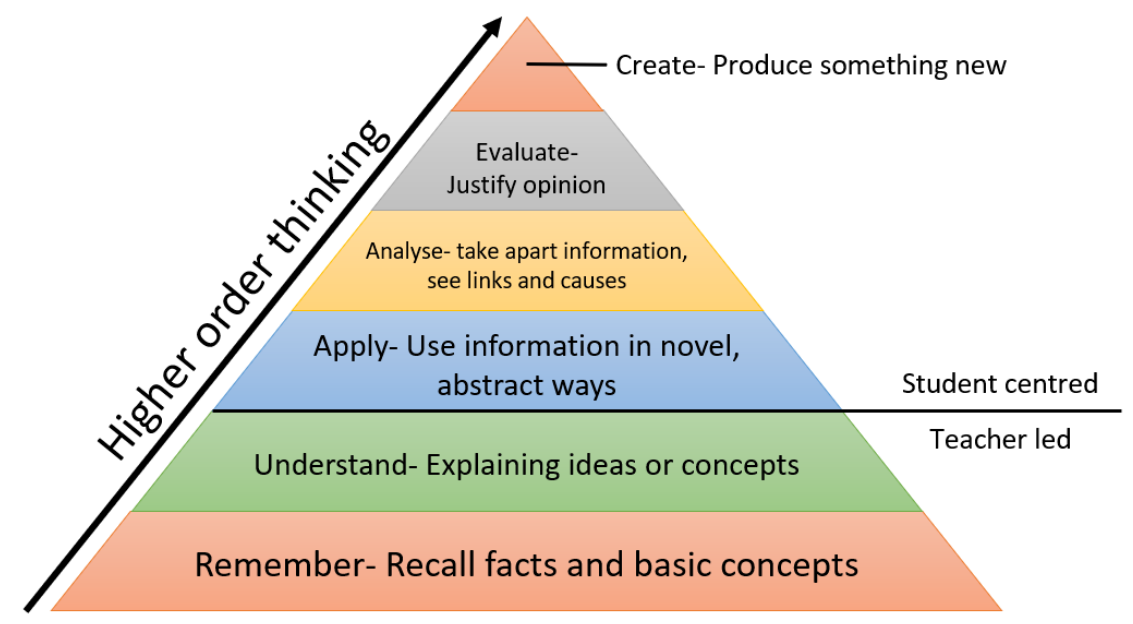


For this education to be truly effective, the teaching must achieve a fundamental understanding of scientific concepts, which can be applied to practice. To achieve this, students must be able to: remember, understand, apply, analyse and evaluate the material taught to them, representing 5/6 of Bloom's cognitive dimensions (Figure 1). Laboratory sessions are also particularly useful and valuable teaching sessions as they incorporate many different learning styles, including Visual, Aural, Reading/Writing and Kinaesthetic $(\text { VARK) })^{3}$.

Evidence suggests that active learning methodologies such as those used in laboratory teaching, are better than large group didactic teaching in fostering learning to achieve fundamental understanding. ${ }^{4-10}$ Student satisfaction with active learning can vary, however the overall trend in healthcare teaching is an increase in student satisfaction. ${ }^{11-13}$ The use of active learning has been shown to improve student understanding and performance during assessments. Nevertheless, pharmacy student engagement in science education (rather than active learning) is seen to be variable. ${ }^{5,14-16} \mathrm{~A}$ key challenge then is how to increase engagement in science education, including laboratory sessions. One anecdotal reason for lack of student engagement in laboratory sessions, is a difficulty seeing the relevance of learning the scientific concepts for future practice. ${ }^{14,15,17}$ Effective integration of practice with laboratory science teaching is a reasonable strategy to improve this. ${ }^{18-22}$ This will allow the information to be understood in context by the student and ensure they have a fundamental understanding of the science behind their practice. Harrold (2010) implemented the contextualization in various forms, using a workshop that related laboratory teaching on genetics to practice relevant diseases on a doctor of pharmacy programme..$^{20,21}$ The contextualization of the information presented in laboratory sessions may be thought of as a "nesting" level of integration, according to Harden's ladder of integration. ${ }^{23}$ Integrated teaching has been adopted in all UK MPharm courses as required by the GPhC, with the approach differing between schools. ${ }^{24,25}$ Some schools opted for a fully inter-disciplinary approach from year one, whilst other schools kept the earlier years of the course less integrated and utilised levels such as "nesting", where the teaching of one discipline is enhanced by including material from other disciplines; and "temporal coordination" where each discipline continues to be taught separately, but with relevant subjects across disciplines timetabled to co-inside with each other. They then move towards inter and trans-disciplinary levels in later years, around themes such as body systems or age. ${ }^{25-27}$ Evidence for how best to implement integration for science and laboratory 
teaching to optimise learning and performance, and the impact of integrated assessment is however lacking; this study, therefore, seeks to contribute to the evidence on the use of integration in the formative assessment of pharmacy students and its impact on achievement and engagement in their science education. ${ }^{25}$

\section{Objectives}

The main objectives were to investigate:

- $\quad$ Students' median performance in formative assessment

- Students' achievement of full marks in formative assessment

- $\quad$ Students' engagement in laboratory classes

The key research questions were:

What was the impact of integrated post-laboratory assessment on:

a) Students' overall performance in formative assessment?

b) Students' achievement of full marks in formative assessment?

c) Students' engagement in laboratory classes?

\section{Three hypotheses, relative to the key research questions, tested in this study were:}

a) Null hypothesis $(\mathrm{H} 10)$ : There was no significant difference in achievement between integrated and nonintegrated assessment. The alternative hypothesis $\left(\mathrm{H} 1_{1}\right)$ : there was a significant difference in performance between integrated and non-integrated assessments;

b) Null hypothesis $\left(\mathrm{H}_{2}\right)$ : the integration of assessment has no impact on the achievement of full marks. The alternative hypothesis $\left(\mathrm{H}_{2}\right)$ : the integration of assessment has an impact on the achievement of full marks

c) Null hypothesis $\left(\mathrm{H}_{3}\right)$ : there was no significant difference in student engagement when taking the integrated or non-integrated post-laboratory assessment. The alternative hypothesis $\left(H 3_{1}\right)$ : there was a significant difference in student engagement when taking the integrated or non-integrated post-laboratory assessment. 


\section{Methods}

\section{Study design}

This was a randomised cross-over study, with participants randomly assigned to two groups (A or B). After completing four laboratory classes (identical for all participants), students received post-laboratory assessments consisting of two questions, that were divided in two domains: calculation and knowledge application (KA). The students took the assessments online using the web platform, Qualtrics@. Group A received integrated assessments for laboratory classes one and two, and non-integrated assessments for sessions three and four; group B received the reverse of this. After completing the assessment for session two, all participants also completed an adapted version of the ASPECT questionnaire to determine student engagement in the sessions (Figure 2)

Figure 2: Flow chart of study design. Numbered " $T$ " letters indicate significant time points in the study, with cross-over at $\mathrm{T} 2$

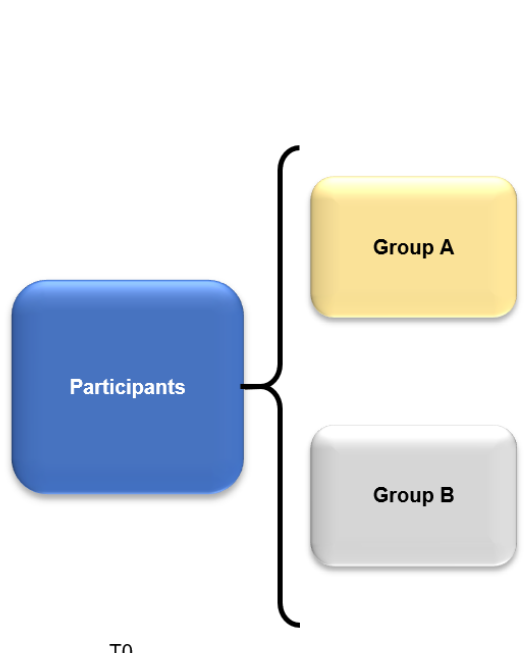

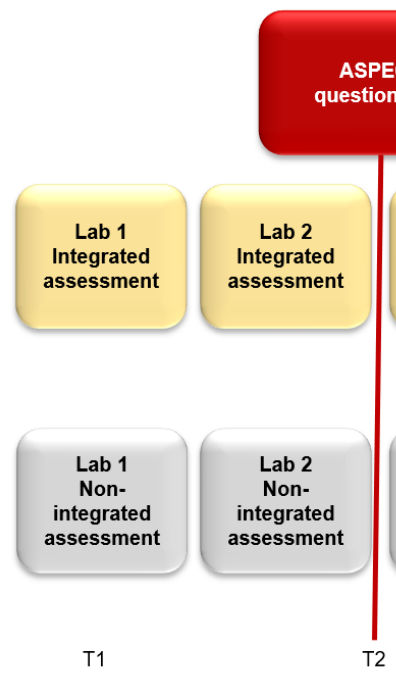

ASPECT

questionnaire

T0

T1

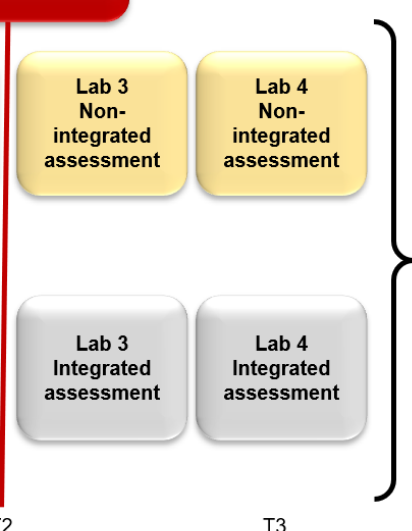

T3
Analysis

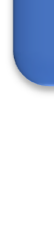

$\mathrm{T} 4$

Abbreviation ASPECT stands for "Assessing Student Perspective of Engagement in Class Tool"

The integrated questions were written such that the basic science principle was contextually presented (put into a real situation) within and directly linked to a plausible real-world scenario easily showing why the knowledge being tested was important to the students' future practice. The non-integrated questions had no real world contextualization, nor rationale as to why the information was important; an example of the questions can be seen in Figure 3.The framework of the study design in medical research outlined by Dawson and Trapp informed the design of our study. ${ }^{28} \mathrm{~A}$ cohort cross-over study was chosen as it provided 
more robust evidence than a simple observational cohort study, and with subjects randomly assigned to two cohort arms aiming to minimise bias.

Figure 3: Example of equivalent integrated (A) and non-integrated (B) questions

A

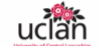

A 40-year-old male patient comes into the pharmacy and

explains that he has been gargling with aspirin (an analgesic.

with anti-inflammatory properties) for a few days for swollen

tonsils and that it isn't working. After talking to him, you determine

that he has been using a non-dispersible formulation and as

such not enough drug has been in the water that he has gargled

with. With your knowledge from the lab session you know that the

solubility of many drugs is an issue in how they are delivered,

and there are various strategies for modifying it.

Which of the following is the most suitable excipient to

increase the concentration of aspirin in the water the

patient is gargling with?

$O$ cellulose

O citric acid

O Glucose

O Lactose

O sodium dodecyl sulphate
B

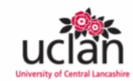

Which of the following is the most suitable excipient to increase the concentration of aspirin in water?

Cellulose

Citric acid

Glucose

Lactose

Sodium dodecyl sulphate

\section{Study setting}

The study ran throughout a series of four laboratory sessions with each student completing a postlaboratory assessment in the two weeks following a session.

Locations

The study was conducted at the University of Central Lancashire, Preston UK.

\section{Relevant dates}

The study was conducted during the spring term (February-March) of the academic year 2019/20.

\section{Period of recruitments}

Participants were recruited in January 2020.

\section{Exposure}

All students were exposed to integrated and non-integrated sessions according to the study design (Figure 2).

\section{Follow-up}

All students were followed up according to the study design (Figure 2).

Data collection

Data was collected using an online web platform called Qualtrics ${ }^{\odot}$. 


\section{Participant eligibility criteria}

Participants were enrolled in the first year of study on the Master of Pharmacy (MPharm) degree. After the second laboratory session (T2, Figure 2), participants were invited to complete an adapted version of the ASPECT questionnaire, in February 2020.

\section{Variables and measurement}

Primary outcome

The primary outcome of this study was the total scores obtained by the students in the integrated and non-integrated questions, which was evaluated by comparing the medians and interquartile ranges (IQR) of the respective total scores.

\section{Secondary outcomes}

Full marks

The number of students' achieving full marks in formative assessment was investigated. A minimum score of 0 (zero) and the maximum score of four (4) was possible. Therefore, we compared the number of students who achieved the maximum scores in the integrated session versus the non-integrated sessions. Student engagement

Student engagement was assessed according to the three domains of an adapted and approved versions of the ASPECT questionnaire developed by Wiggins et al. (2017) which uses a five-point Likert scale (e-Appendix 1). ${ }^{29}$ The three domains were: "Instructor contribution", "Value of activity" and "Personal effort".

\section{Bias}

Due to practical constraints of laboratory size and timetabling, each of the four laboratory teaching sessions was delivered in three separate sessions to a third of the cohort each time, divided by their registration group. While these sessions were delivered to a protocol, there was the possibility that attendance at different sessions would cause a bias. To minimise this effect, students from both groups $A$ and B were spread out across all three sessions, and the same member of staff delivered every laboratory session. The questions received by group $A$ and $B$ vary, with group $A$ receiving the integrated version during the first two laboratories and group B the integrated version during the last two. This approach could have introduced a potential bias based on the relative difficulty of the questions for each laboratory. To minimise this, the questions for each laboratory followed a similar format. They were also independently verified for 
equivalent difficulty by three academics within the school who teach on the pharmacy course. The total scores achieved after receiving both integrated and non-integrated assessments were analysed to determine if there was any significant effect between groups.

Ethics approval

This study was conducted following the Helsinki declaration of 1975 as reviewed in 2008 and received ethical approval from Health Ethics Review Panel of the University of Central Lancashire on January 6th, 2020 (ref: HEALTH 0029).

Informed consent and GDPR

Informed consent was obtained from all individual participants included in the study. All data were handled following the requirements of the Data Protection Act (2018) and/or the General Data Protection Regulation (GDPR) 2016 according to European Union law; therefore, data were anonymised and stripped of any identifiable references to the participants.

\section{Participants, study size and power}

Participants and descriptive data

An initial recruitment of 60 students was made from a cohort of 129 students, representing a sign-up rate of $46.5 \%$ (Figure 4). Of those 60 students, 30 went on to complete the study and were included in the final analysis, giving a response rate of $50 \%(30 / 60)$. The final sample of participants was represented by $10(33.3 \%)$ male and $20(66.7 \%)$ female $(p=0.068)$ students, this ratio is reflective of the student cohort in the MPharm degree at UCLan.

Figure 4. Strengthening the Reporting of Observational Studies in Epidemiology (STROBE) flow diagram

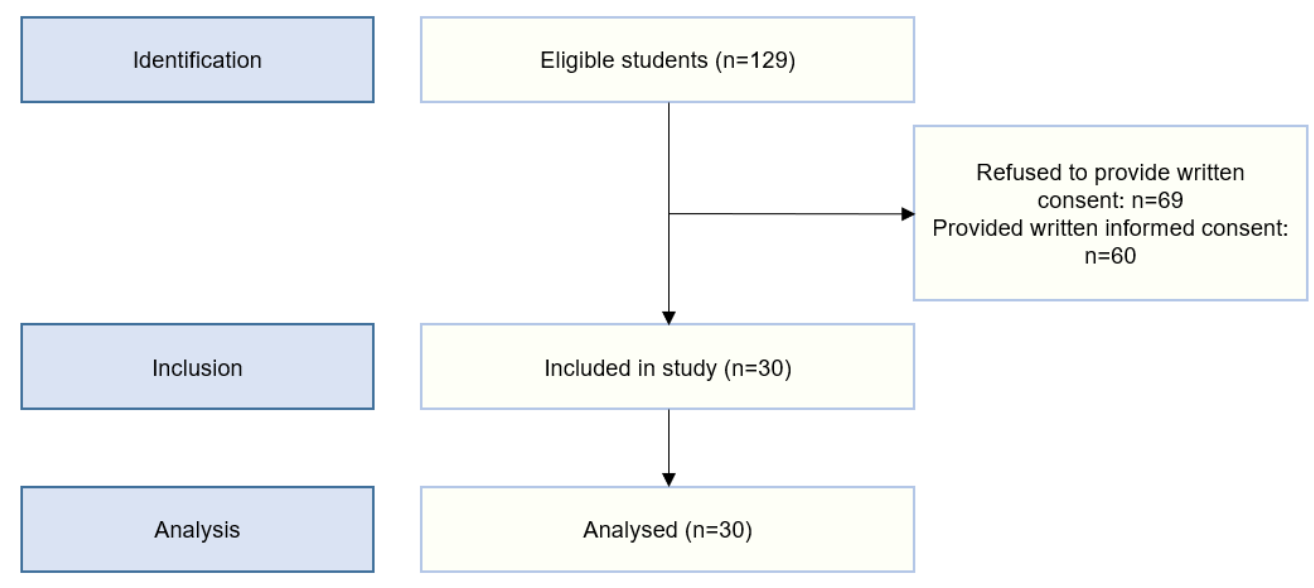


There are different approaches to sample size for pilot studies, and Lancaster et al. (2004) ${ }^{30}$ suggested that a sample of 30 is acceptable. The power analysis was conducted for the primary outcome using a posthoc power approach. ${ }^{31}$ Thirty was the number of students who participated in the study. A power of $87 \%$ was obtained using a two-tailed test, with Wilcoxon signed-rank test (matched-pair) for non-normally distributed variables, a calculated effect size (Cohen's d) of 0.6 , an alpha of 0.05 , a critical t value of \pm 2.04 , a non-centrality parameter ( $\delta)$ of 3.21 and 27.64 degrees of freedom (DF). The power analysis was conducted using $G^{*}$ Power version 3.1.9.4.32

\section{Quantitative variables and statistical methods}

\section{Dichotomous variables}

The answers to all the questions were dichotomous (incorrect=0 or correct=1). Pearson's Chi-square for the goodness of fit was used to estimate a statistical difference between gender. Categorical unpaired data $(0 ; 1)$, such as the responses of group A and B were compared and using Pearson's Chi-square for independence, or Fisher exact test for items. Odds ratios and 95\% confidence intervals were also calculated. Adedokum and Burgess (2012) suggested that the pre-post differences in dichotomous items (e.g., "correct=1" or "incorrect=0") needs to be tested using the McNemar's test. ${ }^{33}$ Still, many scholars have noted the inappropriate use of Pearson's Chi-square test to evaluate this type of analysis. The McNamara's (Chi-square) test is a $2 \times 2$ cross-classification of paired (match) data for a dichotomous item. In our case, due to the small sample size in some cells $(<10)$, we included the Yates correction when conducting the McNamara's test. This correction is calculated as the sum of [(lobserved - expected -0.5$)^{2} /$ expected], where the 0.5 terms, called Yates' correction, is subtracted to adjust for the counts being restricted to integers. ${ }^{34}$ The Cochrane's $Q$ test, which is an extension of the McNamara's analysis, provides a method for testing for differences between three or more matched sets of frequencies or proportions. Therefore, we used this approach for comparing the results obtained during the four integrated and non-integrated questions in each group.

\section{Continuous variables}

Dichotomous variables representing the responses to the questions were computed, generating continuous variables as two total scores, one for the integrated and one the non-integrated assessments. The normality of continuous variables was assessed using the Kolmogorov-Smirnov test; all variables were non-normally distributed. The differences between these two total scores were evaluated using the Wilcoxon sing-rank 
test (paired-data) and expressed using medians and interquartile (IQR) values. A Mann-Whitney $U$ test was conducted to assess the difference between group A and B using the total integrated scores, total nonintegrated scores. The data from the adapted version of the ASPECT questionnaire were analysed by means of descriptive statistics, median and IQR, which were produced for every question. Questions were categorised by their domains (as set out by Wiggins et al. (2017) ${ }^{29}$ of "Instructor contribution", "Value of activity" and "Personal effort". Responses between groups that had received integrated questions and nonintegrated questions were compared by domain, using the Mann-Whitney-U test.

\section{Linear regression}

Two linear regression models were built for assessing the relationship between the number of students and their scores achieved in the integrated versus the non-integrated sessions, respectively. The general equation of the linear model is $y_{i}=b_{0}+b_{1} x_{i}+\varepsilon_{i}$, which was rearranged according to our requirements using the following values $y_{i}=$ student numbers, $b_{0}=$ intercept; $b_{1}=$ gradient; $x_{i}=$ scores; $\varepsilon_{i}=$ error. Therefore, our equation was represented by student numbers $=b_{0}+b_{1}$ scores $+\varepsilon_{\text {i.. }}$ The model fit was assessed using the coefficient of determination $\left(R^{2}=S S_{M} / S S_{T}\right)$ obtained by dividing the sum of the squares for the model $\left(S_{M}\right)$ by the total sum of the squares (SST). $R^{2}$ expressed as a percentage, represents the amount of variance of the outcome explained by the model $\left(\mathrm{SS}_{\mathrm{M}}\right)$ relative to how much variation there was explained in the first place (SST). So, $\mathrm{R}^{2}$ represents the proportion of the variation in the outcome that can be predicted from the model. ${ }^{35}$

Missing data

The data set did not have missing data Statistical significance

The results were considered statistically significant with a P-value $<0.05$. Software used for the analysis

All the analyses were conducted with Excel for MS Office 16 and SPSS 26 (SPSS version 26; IBM Corp., Armonk, NY, USA).

\section{Results}

\section{Primary outcome}

Total scores obtained by the students in the integrated and non-integrated questions. 
The range of the total scores for the integrated assessment was $3(1-4)$, and $4(0-4)$ for non-integrated assessment. The median of the total score for the integrated assessment was 3.5 (IQR=2.00-4.00), the median of the total score for the non-integrated assessment was 2.00 (IQR=1.75-3.00). The difference in total score achieved between integrated and non-integrated questions was statistically significant $(p=0.003)$.

\section{Secondary outcomes}

\section{Assessment performance between integrated and non-integrated questions}

The results of comparing student's performance in each question, integrated versus non-integrated, are shown in Table 1. Seven questions did not show statistically significant differences; only question six had a statistically significant difference $(p=0.026)$.

Table 1. Integrated versus non-integrated questions

\begin{tabular}{|c|c|c|c|c|c|}
\hline \multirow[b]{2}{*}{ Question } & \multicolumn{3}{|c|}{ Assessment } & \multirow[b]{2}{*}{ OR $(95 \% \mathrm{Cl})$} & \multirow[b]{2}{*}{ p-value } \\
\hline & & A- Integrated $\mathbf{n}(\%)$ & B- Non-integrated n (\%) & & \\
\hline \multirow{2}{*}{1} & Correct & $12(85.7)$ & $11(68.8)$ & \multirow{2}{*}{$0.369(0.59-2.292)$} & \multirow{2}{*}{0.399} \\
\hline & Incorrect & $2(14.3)$ & $5(31.3)$ & & \\
\hline \multirow{2}{*}{2} & Correct & $13(92.9)$ & $14(87.5)$ & \multirow{2}{*}{$0.538(0.043-6.668)$} & \multirow{2}{*}{1} \\
\hline & Incorrect & $1(7.1)$ & $2(12.5)$ & & \\
\hline \multirow{2}{*}{3} & Correct & $13(92.9)$ & $10(62.5)$ & \multirow{2}{*}{$0.128(0.013-1.243)$} & \multirow{2}{*}{0.086} \\
\hline & Incorrect & $1(7.1)$ & $6(37.5)$ & & \\
\hline \multirow{4}{*}{4} & Correct & $10(71.4)$ & $7(43.8)$ & \multirow{2}{*}{$0.311(0.068-1.427)$} & \multirow{2}{*}{0.159} \\
\hline & Incorrect & $4(28.6)$ & $9(56.3)$ & & \\
\hline & & A- Non-integrated n (\%) & B- Integrated & OR (95\% Cl) & n-value \\
\hline & & & $n(\%)$ & (וס ש & pratiue \\
\hline \multirow{2}{*}{5} & Correct & $9(64.3)$ & $10(62.5)$ & \multirow{2}{*}{$0.926(0.209-4.108)$} & \multirow{2}{*}{1} \\
\hline & Incorrect & $5(35.7)$ & $6(37.5)$ & & \\
\hline \multirow{2}{*}{6} & Correct & $4(28.6)$ & $12(75.0)$ & \multirow{2}{*}{$\begin{array}{r}7.500(1.484- \\
37.905)\end{array}$} & \multirow{2}{*}{0.026} \\
\hline & Incorrect & $10(71.4)$ & $4(25.0)$ & & \\
\hline \multirow{2}{*}{7} & Correct & $10(71.4)$ & $9(56.3)$ & \multirow{2}{*}{$0.514(0.112-2.359)$} & \multirow{2}{*}{4.666} \\
\hline & Incorrect & $4(28.6)$ & $7(43.8)$ & & \\
\hline \multirow{2}{*}{8} & Correct & $12(85.7)$ & $15(93.8)$ & \multirow{2}{*}{$\begin{array}{r}2.500(0.202- \\
30.998)\end{array}$} & \multirow{2}{*}{0.586} \\
\hline & Incorrect & $2(14.3)$ & 1(6.3) & & \\
\hline
\end{tabular}

OR: Odd ratios; Statistical significance was calculated using Pearson's Chi-square or Fisher Exact Test; $p<0.05$

Achievements of full marks

The scores possible for each student ranged from 0 (lowest) to 4 (full marks) in both integrated and non-integrated assessment (each student received eight questions). Twenty-five (83.3\%) students achieved full scores in the integrated assessment, compared to only five (16.7\%) to the non-integrated. A 
statistically significant difference was found between the integrated and non-integrated assessments $(p=0.006)$.

Figure 5 shows the difference between the integrated and non-integrated assessment according to the frequency of the final score for each, with linear regressions fitted. The equation of the line for integrated scores shows a steeper gradient $\left(b_{1}=3.4\right)$ and a higher $R^{2}$ than for the non-integrated assessment $\left(b_{1}=0.7\right)$. The higher coefficient of determination $\left(\mathrm{R}^{2}\right)$ of the integrated session shows a higher predictive power $\left(R^{2}=0.903 ; 90.3 \%\right)$ compared to the respective one shown in the non-integrated sessions $\left(R^{2}=0.122\right.$; $12.2 \%)$.

Figure 5: Property fitting of the total score of integrated and non-integrated assessments

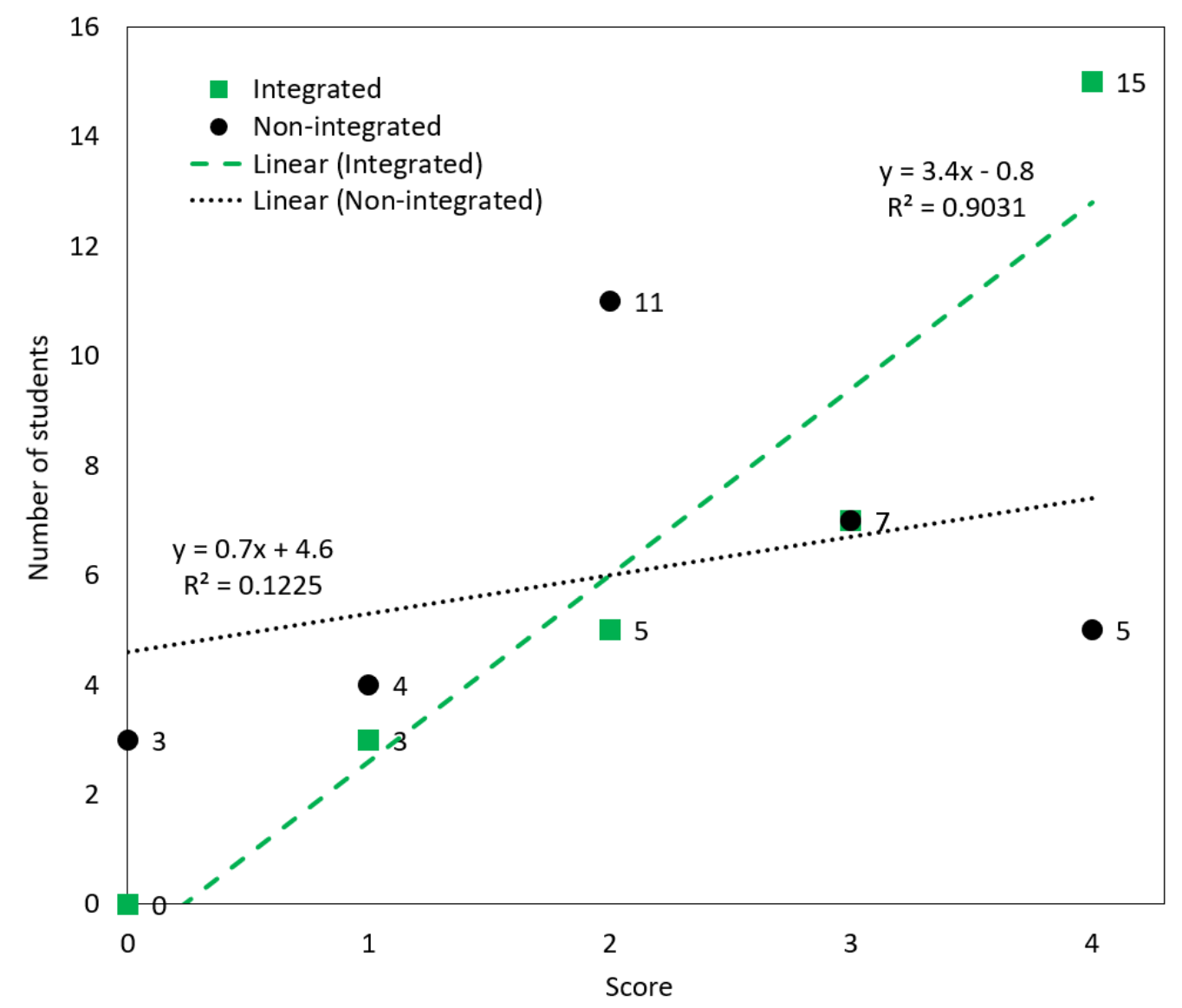

\section{Calculation questions}

Two calculations questions were compared (Q4, Q7); the number of students taking the integrated questions who were correct was 19 (63.3\%), while those who received the non-integrated was 17 (56.7\%). This difference was not statistically significant $(p=0.804)$. 


\section{Knowledge application questions}

Four questions that tested the students' ability to apply scientific knowledge were analysed, comparing the integrated and non-integrated scores achieved by students. Table 2 shows a statistically significant difference between the integrated and the non-integrated assessments $(p=0.006)$.

Table 2. Applied knowledge in integrated versus non-integrated sessions

\begin{tabular}{lccc} 
& KA integrated & KA non-integrated & p-value \\
\hline Scores & $\mathrm{n}(\%)$ & $\mathrm{n}(\%)$ & 0.006 \\
\hline 0 & $2(6.7 \%)$ & $4(13.3)$ & \\
\hline 1 & $6(20.0)$ & $10(33.3)$ & \\
\hline 2 & $22(73.3)$ & $16(53.3)$ & \\
\hline
\end{tabular}

aFisher Exact test; $p<0.05$

\section{Performance between cohort arms}

Table 3 shows that in the integrated assessments, group (cohort) A obtained a higher median (4) score compared to group B (3), but the difference was not statistically significant $(p=0.166)$. A statistically significant difference was found only in the total achieved in the non-integrated assessment. The median value of the total integrated plus non-integrated scores did not show a statistically significant difference between the two groups.

Table 3. Comparison of the three total scores

\begin{tabular}{lrrr}
\hline Question scores & \multicolumn{1}{c}{ Group A } & Group B & \multirow{2}{*}{ p-value } \\
& median (IQR) & median (IQR) & \\
\hline Total integrated & $4.0(3.0-4.0)$ & $3.0(2.0-4.0)$ & 0.166 \\
\hline Total non-integrated & $2.0(1.0-2.3)$ & $3.0(2.0-4.0)$ & 0.035 \\
\hline $\begin{array}{l}\text { Total integrated plus non- } \\
\text { integrated }\end{array}$ & $5.5(4.78-6.3)$ & $5.5(4-7.8)$ & 0.768 \\
\hline
\end{tabular}

aMann-Whitney U Test; $p<0.05$

\section{Student engagement}

The median value to each question on the ASPECT questionnaire for groups A and B (who had at this point only received integrated and non-integrated assessment, respectively) is shown in Figure 6 . The range of responses for the integrated and non-integrated groups was 4 (from 2 to 5). A difference was found between integrated and non-integrated groups for "Instructor contribution" ( $p=0.011)$ and "Value of activity" $(p=0.011)$. No significant difference was found in Personal effort $(p=0.174)$, Table 4 . 
Figure 6. Responses to ASPECT questionnaire

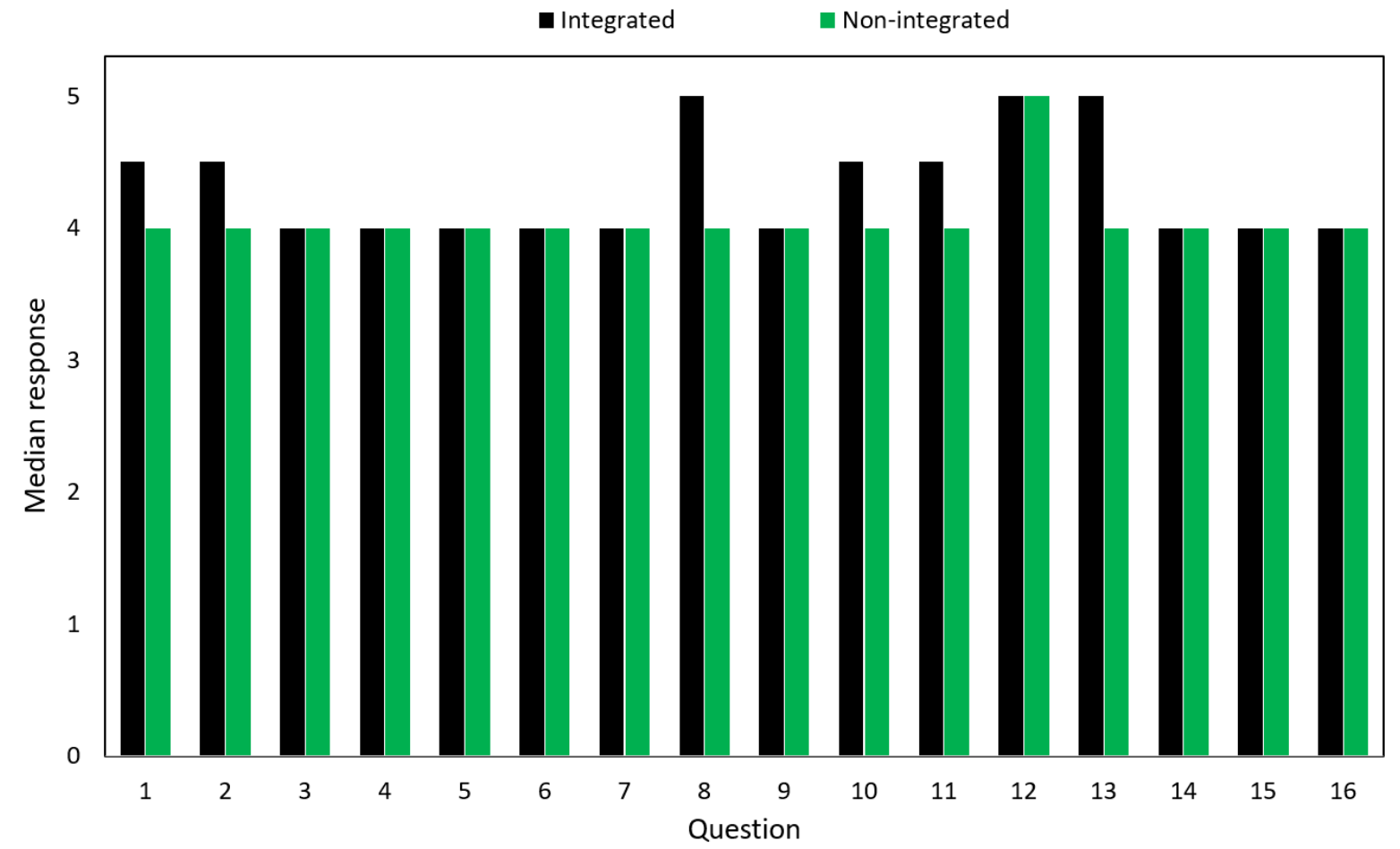

Abbreviation ASPECT stands for "Assessing Student Perspective of Engagement in Class Tool"

Table 4. ASPECT's domains scores

\begin{tabular}{|c|c|c|c|}
\hline Domain & $\begin{array}{l}\text { Integrated } \\
\text { median score (IQR) }\end{array}$ & $\begin{array}{l}\text { Non-integrated } \\
\text { Median score (IQR) }\end{array}$ & p-value ${ }^{a}$ \\
\hline Instructor contribution & $5.0(4.0-5.0)$ & $4.0(4.0-4.0)$ & 0.011 \\
\hline Value of activity & $4.0(4.0-5.0)$ & $4.0(3.0-4.0)$ & 0.011 \\
\hline Personal effort & $4.0(4.0-5.0)$ & $4.0(4.0-5.0)$ & 0.174 \\
\hline
\end{tabular}

${ }^{a}$ Mann-Whitney U Test; $p<0.05$

\section{Discussion}

\section{Performance in post-laboratory assessment}

The results of this study suggested that the integrated assessment had a positive and statistically significant impact on student performance. A statistically significantly higher number of students achieved full marks in the integrated assessment compared to the non-integrated. Also, a statistically significant increase in the median score was observed from the integrated questions compared to the non-integrated ones (3.5 out of 4 , compared to 2 out of $4, p=0.003$ ). These results suggest that the use of integrated questions alone as post-laboratory assessment, can enhance students' ability to understand a question and potentially improve their overall performance. This was achieved without any changes in content or 
level of integration in the laboratory teaching. This is of particular interest as laboratory classes are often taught by non-pharmacist staff, who may struggle to integrate content past the "nesting" level of integration, without professional staff being present during the session.

Pharmacy students have previously reported difficulty in interpreting multiple choice questions (MCQ's), so any technique that could improve question comprehension would be beneficial. ${ }^{36}$ The results of the linear regression models demonstrated that the integrated questions had a higher predictability power. The steeper gradient of the integrated regression compared to the non-integrated suggests that students are more likely to gain full marks when taking an integrated assessment; a result that is supported by the McNamara's test. These results suggest that overall understanding and comprehension of questions was consistently improved when using a contextualized, integrated question style; therefore, adoption of such a question style may help address the reported difficulty in MCQ comprehension.

These results are in agreement with those reported by Hansen et al. (2013) ${ }^{19}$; they showed a statistically significant increase in pharmaceutics test scores in students who had received a workshop integrating pharmaceutics and practice over those who had not. The key difference in this study being that the intervention was the laboratory session and not in the assessment. Similarly, Autumn et al. (2011) ${ }^{37}$ reported a significant increase in test performance after students had completed an essay and calculations linking pharmaceutical concepts with patient safety. The interventions by Hansen et al., $(2018)^{19}$ and by Autumn et al.,(2011) 36 are larger and harder to implement than what is presented here. However, the trend of improved marks after and during integrated assessment remains the same. What is key here, is the comparable improvement in student engagement and achievement shown with the smaller and more reproducible intervention of a short, integrated formative assessment, whilst making no changes to the laboratory session itself. This shows the value of effective integration of science and practice on student achievement, not only in teaching but also in assessment.

Looking deeper at the results, the knowledge application questions when analysed alone showed a statistically significant difference, while the calculation questions did not. One potential reason for this is that knowledge application questions provide students with a relevant practice-based scenario which can spark connections to other subject areas, enabling students to "sense check" their answer based on practical experience. Calculation questions, however, generally require students to take given figures and 
process them in a formulaic way; therefore, the benefit of context may be reduced in terms of achievement, though not necessarily engagement.

\section{Performance between cohort arms (bias)}

The overall scores between groups $A$ and $B$ were not significantly different once they had both received integrated and non-integrated assessments. This suggests that while there was an unavoidable difference in how the groups were treated (receiving integrated and non-integrated questions at different points) the student's allocation to group A or B did not advantage or disadvantage them. Some inconsistency can still be seen in performance in non-integrated questions. However, it was not possible to assign this difference to any one factor. Nevertheless, when adding the total scores of the integrated and the non-integrated questions the median in both groups was the same (5.5), suggesting that the study did not advantage or disadvantage one of the two groups.

\section{Student engagement}

Questions were categorised according to three domains: instructor contribution, value of activity, personal effort. Here a significant difference in the distribution of responses could be seen, with those students who had received integrated post-laboratory assessment giving more positive responses in the domains of instructor contribution and value of activity $(p=0.011$ in both cases). This indicates that by receiving the integrated post-laboratory assessment, students further appreciated the value of the laboratory sessions. The personal effort domain did not show a statistically significant difference. The results from the ASPECT questionnaire are broadly in agreement with previous studies, showing good levels of engagement in active learning activities amongst pharmacy students. This was demonstrated recently in a study conducted by Manfrin et al., (2019), showing that both students and staff at a UK school of pharmacy valued active learning activities. ${ }^{15}$ The results from this study, are of further interest, as they show that integrated assessment alone as in intervention, without any changes to the laboratory session, can increase student engagement and ability to see the relevance of laboratory classes.

Previous studies have shown a variable attitude towards science education amongst pharmacy students (rather than active learning), particularly when related to their prospective careers. ${ }^{14,16,17}$ Wehle and Decker (2016) $)^{17}$ found, in German pharmacy students, that whilst student attitudes towards the relevance of chemistry to their degree programme was good, their attitudes of its relevance for their career were far worse and less consistent. A similar study by Prescot et al. (2014) ${ }^{14}$ surveyed 254 UK pharmacy 
students' perceptions of the relevance of science and mathematics subjects to a career in pharmacy; and found similar attitudes particularly in the earlier years of the pharmacy course. The improvement in attitude observed in this study amongst first-year pharmacy students then shows the potential for integrated laboratory assessment as an intervention in addressing the issue of early year pharmacy student attitudes towards science education, without having to make large changes to the laboratory class itself.

\section{Limitations}

The main limitation of this study could be due to the sample size of 30 students. However, this was a pilot study, which we intend to repeat with larger sample size. There is still the bias of performance based on which cohort arm a student was placed in. This cannot be avoided in an observational study. However, it could be mitigated by assessment for each laboratory session following a similar format and undergoing independent review. Another option to avoid this bias is designing a cross-over randomised controlled trial, as suggested by Dwan et al. (2019). ${ }^{38}$

\section{Conclusions}

The overall conclusions from this study are that the use of short, formative integrated assessment of science teaching alone on a pharmacy course, increased the achievement of students without having to make any amendment to laboratory classes. Contextualized post-laboratory assessments may also be of use in improving student engagement in laboratory classes by integrating science teaching into practice. This suggests that integrated post-laboratory assessment may be a simple and effective intervention to improve pharmacy students' achievement and engagement in science classes.

The department of mathematics of the Furman University (USA) is suggesting that a small cohort analysis does not preclude generalizability. ${ }^{39}$ To add to this, the department of mathematical Science, University of Bath (UK) is suggesting that small data is sometimes preferable to big data and that the high quality of a small sample can produce superior inferences to a low-quality large sample. ${ }^{40}$ However, the results of this study will inform the design of more extensive research involving pharmacy students in the UK.

\section{Other information}

Funding

No external funding was received for this study. 


\section{References}

1. Waterfield J. Is pharmacy a knowledge-based profession? Am J Pharm Educ. 2010;74(3):50. https://doi.org/10.5688/aj740350.

2. Council GP. Future pharmacists: Standards for the initial education and training of pharmacists. GPhC. 2011.

3. Marcy V. Adult learning styles: How the VARK Learning Styles Inventory can be used to improve student learning. Perspectives on Physician Assistant Education. 2001;12(2):117-120.

4. Singh K, Mahajan R, Gupta P, Singh T. Flipped classroom: a concept for engaging medical students in learning. Indian pediatr. 2018;55(6):507-512. https://doi.org/10.1007/s13312-0181342-0.

5. Freeman S, Eddy SL, McDonough M, et al. Active learning increases student performance in science, engineering, and mathematics. PNAS. 2014;111(23):8410-8415. https://doi.org/10.1073/pnas.1319030111.

6. Miller CJ, Metz MJ. A comparison of professional-level faculty and student perceptions of active learning: its current use, effectiveness, and barriers. Adv Physiol Educ. 2014;38(3):246-252. https://doi.org/10.1152/advan.00014.2014.

7. Ofstad W, Brunner LJ. Team-based learning in pharmacy education. Am J Pharm Educ. 2013;77(4):70. https://doi.org/10.5688/ajpe77470.

8. Tangiisuran B, Tye SC, Tan KW. Implementation and assessment of flipped classroom learning on medication distribution system to pharmacy undergraduates. Pharm Educ. 2017;17.

9. Bland M, Saunders G, Frisch JK. In defense of the lecture. J Coll Sci. 2007;37(2):10.

10. Bradbury NA. Attention span during lectures: 8 seconds, 10 minutes, or more? In: American Physiological Society Bethesda, MD; 2016.

11. Manfrin A, Wadiwala S, Apampa B. Students and faculty perception of Active Learning: a case study. Student Engagement in Higher Education Journal. 2019;3(1):213-230. Retrieved from http://195.201.33.159/raise/article/view/1012. 
12. Deslauriers L, McCarty LS, Miller K, Callaghan K, Kestin G. Measuring actual learning versus feeling of learning in response to being actively engaged in the classroom. PNAS. 2019;116(39):19251-19257. https://doi.org/10.1073/pnas.1821936116.

13. Kilgour JM, Grundy L, Monrouxe LV. A rapid review of the factors affecting healthcare students' satisfaction with small-group, active learning methods. Teach Learn Med. 2016;28(1):15-25. https://doi.org/10.1080/10401334.2015.1107484.

14. Prescott J, Wilson SE, Wan K-W. Pharmacy students' perceptions of natural science and mathematics subjects. Am J Pharm Educ. 2014;78(6). https://doi.org/10.5688/ajpe786118.

15. Smith JR, Chungh MK, Sadouq S, Kandiah A. Enhancing the chemistry experience of undergraduate pharmacy students. Paper presented at: International Education Conference2015.

16. Hastings JK, West DS, Hong SH. Changes in Pharmacy Student Motivation During Progression Through the Curriculum. Am J Pharm Educ. 2005;69(2):251-255. https://doi.org/10.5688/aj690238.

17. Wehle S, Decker M. Perception of the relevance of organic chemistry in a German pharmacy students' course. Am J Pharm Educ. 2016;80(3):1-7. https://doi.org/10.5688/ajpe80340.

18. Alsharif NZ, Roche VF, Qi Y. Students' perception of self-efficacy following medicinal chemistry skills laboratory exercises. Am J Pharm Educ. 2016;80(5):76-88. https://doi.org/10.5688/ajpe80576.

19. Hansen D, Tummala H, Jensen-Bender W, Meyer BA, Ngorsuraches S. Evaluating Student Performance and Perception of a Workshop Integrating Pharmacy Practice and a Pharmaceutics Lab. Innov Pharm. 2018;9(3):7-7. https://doi.org/10.24926/iip.v9i3.1387.

20. Harrold MW, McFalls MA. A pharmacy practice laboratory exercise to apply biochemistry concepts. Am J Pharm Educ. 2010;74(8):144. https://doi.org/10.1152/advan.00014.2014.

21. Kolluru S, Roesch DM, Akhtar de la Fuente A. A multi-instructor, team-based, active-learning exercise to integrate basic and clinical sciences content. Am J Pharm Educ. 2012;76(2):33-40. https://doi.org/10.5688/ajpe76233. 
22. Pearson ML, Hubball HT. Curricular integration in pharmacy education. Am J Pharm Educ. 2012;76(10):204-212. https://doi.org/10.5688/ajpe7610204.

23. Harden RM. The integration ladder: a tool for curriculum planning and evaluation. Med Educ. 2000;34(7):551-557. https://doi.org/10.1046/j.1365-2923.2000.00697.x.

24. Husband AK, Todd A, Fulton J. Integrating science and practice in pharmacy curricula. Am J Pharm Educ. 2014;78(3):63-71. https://doi.org/10.5688/ajpe78363.

25. Council GP. Supplementary guidance for schools of pharmacy on integration. GPhC. 2011.

26. Barlow JW, Strawbridge JD. Teaching and assessment of an innovative and integrated pharmacy $\begin{array}{llll}\text { undergraduate } \quad \text { Pharm } & \text { Educ. }\end{array}$ https://doi.org/10.1080/15602210701256997.

27. Wensel TM, Broeseker AE, Kendrach MG. Design, implementation, and assessment of an integrated pharmacy applications course series. Currents in Pharmacy Teaching and Learning. 2014;6(5):706-715. https://doi.org/10.1016/i.cptl.2014.05.018.

28. Dawson B, Trapp RG. Basic and clinical biostatistics. Singapore. 2004;2001.

29. Wiggins BL, Eddy SL, Wener-Fligner L, et al. ASPECT: A survey to assess student perspective of engagement in an active-learning classroom. CBE Life Sci Educ. 2017;16(2):1-13. https://doi.org/10.1187/cbe.16-08-0244.

30. Billingham SA, Whitehead AL, Julious SA. An audit of sample sizes for pilot and feasibility trials being undertaken in the United Kingdom registered in the United Kingdom Clinical Research Network database. B<C Med Res Methodol. 2013;13(1):104-110. https://doi.org/10.1186/14712288-13-104.

31. Lancaster GA, Dodd S, Williamson PR. Design and analysis of pilot studies: recommendations for good practice. J Eval Clin Pract. 2004;10(2):307-312. https://doi.org/10.1111/1..2002.384.doc.x.

32. Faul F, Erdfelder E, Lang A-G, Buchner A. G* Power 3: A flexible statistical power analysis program for the social, behavioral, and biomedical sciences. Behav Res Methods. 2007;39(2):175-191. https://doi.org/10.3758/BF03193146. 
33. Adedokun OA, Burgess WD. Analysis of paired dichotomous data: A gentle introduction to the McNemar test in SPSS. J Multidiscip Res. 2012;8(17):125-131. Retrieved from https://eric.ed.gov/?id=EJ971707

34. Riffenburgh R. Statistics in medicine 2nd ed. In: Boston, US: Elsevier Academic Press; 2006.

35. Field A. Discovering statistics using IBM SPSS statistics. 4th ed: sage; 2013.

36. Malau-Aduli BS, Preston R, Adu M, et al. Pharmacy students' perceptions of assessment and its impact on learning. Currents in Pharmacy Teaching and Learning. 2019;11(6):571-579.

37. Stewart AL, Buckner IS, Wildfong PL. A shared assignment to integrate pharmaceutics and pharmacy practice course concepts. Am J Pharm Educ. 2011;75(3):1-8. https://doi.org/10.5688/ajpe75344.

38. Dwan K, Li T, Altman DG, Elbourne D. CONSORT 2010 statement: extension to randomised crossover trials. bmj. 2019;366:14378. https://doi.org/10.1136/bmj.14378.

39. Collins J, Brown J, Schammel C, Hutson K, Jeffery W, Edenfield M. Meaningful Analysis of Small Data Sets: A Clinician's Guide. Clinical and Translational Research Graduate Certificate.16.

40. Faraway JJ, Augustin NH. When small data beats big data. Stat Probabil Lett. 2018;136:142-145. https://doi.org/10.1016/i.spl.2018.02.031. 